\title{
Actores y escenarios como determinantes clave de la política de drogas en Perú. El caso de la implementación del control de hoja de coca en el valle del Monzón (2010-2015)+
}

FRANK CASAS*

Pontificia Universidad Católica del Perú

casas.frank@pucp.edu.pe

MARIANA RAMÍREZ**

Pontificia Universidad Católica del Perú

ramirezb.mariana@pucp.pe

https://doi.org/10.18800/rcpg.201701.002

\section{Resumen}

Históricamente, el valle del Monzón desafió la capacidad del Estado peruano. Hasta 2011 dicho territorio era considerado como la cuenca con mayor producción de cultivos ilícitos de coca del Alto Huallaga, y una zona de gran resistencia social frente a las acciones de control. No obstante, desde 2012 esta situación cambió radicalmente. Algunos argumentan que la efectividad de la política fue producto de los altos niveles de acumulación burocrática gestionados por el Estado, tales como mayores recursos económicos para la política, y una alta disposición de instituciones y de funcionarios públicos trabajando en la zona. Sin embargo, el presente estudio muestra que la efectividad política de drogas implementada durante el periodo 2010-2015 en el Monzón se debe a tres factores: i) el enfrentamiento entre dos facciones terroristas que brindaban protección a los gremios contra la erradicación de coca; ii) el debilitamiento de las organizaciones de productores cocaleros, y iii) el apoyo a Devida por parte de empresas privadas contratadas para la implementación del Programa de Desarrollo Alternativo.

Palabras clave: capacidad estatal, política de drogas, cocaína, Monzón, Perú.

\footnotetext{
* Magíster en Ciencia Política y Gobierno por la Pontificia Universidad Católica del Perú (PUCP). Es investigador adjunto del Laboratorio de Criminología y Estudios sobre la Violencia de la PUCP.

** Máster en Estudios Latinoamericanos por la Universidad de Salamanca (España). Es asistente de investigación del Laboratorio de Criminología y Estudios sobre la Violencia de la PUCP.

+Recibido el 15 de febrero de 2017; aceptado el 11 de junio de 2017.
} 
Actors and scenarios as key determinants of drug policy in Peru. The case of the implementation of coca leaf control in the Monzón Valley (2010-2015)

\section{Abstract}

Historically, Monzon Valley has caused great challenges to the Peruvian State capacity. Until 2011, that area was considered as the main area of illicit coca production from the Alto Huallaga, and as an area of high social resistance to the control actions. However, this situation changed radically since 2012. Some may argue that the effectivity of this policy was produced by the high levels from bureaucratic accumulation of the State, such as high level of economic resources for this policy, high institutional disposition, and public officials working in that area. Nonetheless, this research shows that the effectivity of the drug policy implemented in Monzon during 2010-2015 is due to three factors: i) the confrontation between two terrorist factions which protected the cocaleros' guild against the eradication; ii) the weakening from the coca producer's organizations, and iii) the help recived by Devida from private enterprises which were hired for the implementation of the Alternative Development program.

Key words: State capacity, drug policy, cocaine, Monzon, Peru. 


\section{INTRODUCCIÓN}

El valle del río Monzón se encuentra ubicado en la parte noreste de la provincia de Huamalíes, en el departamento de Huánuco, y cuenta con una extensión aproximada de 262435 hectáreas. Hasta el año 2011, dicho valle resultó ser un territorio emblemático para los intereses de los productores de cultivos ilícitos de coca del Alto Huallaga; puesto que Monzón contó con una extensión de coca que representó cerca del $83 \%$ del total de hectáreas producido en todo el Alto Huallaga y el 16\% de la producción nacional, con 10833 ha (Devida, 2013).

A través de la organización gremial denominada «Poderosa Federación de Cocaleros de Monzón» los campesinos cocaleros expresaron su rechazo a cualquier tipo de control de la hoja de coca impulsado por el Gobierno nacional. Para dicho fin, emplearon diversos mecanismos de violencia, tales como las amenazas y agresiones físicas a funcionarios públicos, paralizaciones de vías terrestres, y destrucción de propiedad pública. Asimismo, otra estrategia utilizada por el gremio cocalero para ejercer poder político sobre el Gobierno local fue controlar los accesos del territorio mediante cercos de vigilancia contra visitantes externos. En paralelo, según reportaba la Fiscalía de la Nación, un grupo de dirigentes del gremio cocalero estableció una alianza con remanentes del Partido Comunista del Perú-Sendero Luminoso (PCP-SL), grupo subversivo que operaba en el Alto Huallaga, con el objetivo de adquirir protección armada frente a los intentos del Gobierno nacional para controlar la producción ilícita de coca (CVR, 2003).

En esta línea, el valle del Monzón llegó a convertirse en un símbolo de la debilidad del Estado para controlar el negocio ilegal de la cocaína. Tanto campesinos cocaleros como funcionarios públicos calificaban a Monzón como un territorio inaccesible para el control estatal, al extremo de considerarlo como «tierra de nadie». Sin embargo, hoy la situación del valle ha cambiado significativamente, ya que los cultivos de coca se han reducido considerablemente, el poder político del gremio de cocaleros se ha debilitado, la presencia de remanentes senderistas prácticamente se ha extinguido y las actividades económicas alternativas impulsadas por el Estado se acentúan con mayor sostenibilidad en el territorio. En ese sentido, el presente artículo busca describir cómo intervino el Estado peruano para revertir esta situación y, a su vez, determinar qué elementos permiten explicar la efectividad de la política de control de producción del cultivo de coca implementado en Monzón durante el periodo 2010-2015.

Desde la perspectiva oficial, se suelen resaltar los siguientes elementos de carácter burocrático para explicar la efectiva gestión de la política de control 
de drogas en el valle del Monzón: i) una alta voluntad política del Gobierno nacional, ii) una mayor disposición de recursos logísticos para las acciones de erradicación y de desarrollo alternativo, iii) una alta disposición de instituciones y funcionarios públicos trabajando en el territorio (Devida, 2015). En efecto, dicho planteamiento tiende a resaltar los cambios que han existido, a partir del año 2011, en torno al fortalecimiento de las capacidades para la implementación de dicha política. No obstante, en el presente estudio se propone que las explicaciones basadas en determinantes estatales resultan insuficientes para comprender el contexto del control de drogas en el Monzón, puesto que no consideran la importancia del debilitamiento en las relaciones entre campesinos cocaleros y sus dirigentes gremiales, así como el enfrentamiento entre los líderes senderistas del Huallaga y del VRAE; y finalmente, la contratación de empresas privadas para que implementen las actividades de desarrollo alternativo para cumplir los intereses estatales. Dichos factores resultaron fundamentales para debilitar los mecanismos de resistencia social que anteriormente fueron contraproducentes para los intereses estatales. Por lo tanto, el presente artículo busca comprender el panorama del contexto de lucha contra las drogas en el Monzón, a partir de un análisis del juego político que ejercieron tanto los actores estatales como los no estatales.

\section{MERCADO ILEGAL, TERRITORIO Y CAPACIDAD ESTATAL}

Para el Estado peruano, los territorios cocaleros representan escenarios críticos debido al funcionamiento de una actividad ilegal, la producción de drogas cocaínicas, y la presencia de actores ilegales, terroristas y narcotraficantes, que desafían el Estado de derecho y a la autoridad estatal (Devida, 2015; Zevallos, 2014; Felbab-Brown, 2009; Cabieses, 2000). En efecto, las zonas de producción de cultivos de coca son escenarios de diversas historias de violencia física y estructural que han tenido como eje central el enfrentamiento entre organizaciones criminales y las fuerzas del orden (Kernaghan, 2009; van Dun, 2009; CVR, 2003).

Contextos similares han sido empleados para discutir casos acerca de las limitaciones que tienen algunos Estados para ejercer control sobre su territorio (Dell, 2015). Desde fenómenos de resistencia campesina (Scott, 1985), pasando por los procesos de insurgencia radical (Lombard, 2015; CVR, 2003), hasta la dinámica delincuencial en diversos barrios marginales del continente (Ribando 2014), muchos Estados han tenido dificultades para imponer sus decisiones frente a actores sociales desafiantes (Giraudy y Luna, 2012; Eaton, 2012). 
La literatura especializada de la ciencia política ha contribuido en esta discusión proponiendo casos de estudio donde se evidencian algunas determinantes clave de capacidad estatal que posibilitan la implementación efectiva de sus decisiones sobre el territorio (Davis, 2003, Migdal, 1994). En esa línea, las explicaciones preponderantes que se han empleado para evaluar la capacidad estatal son dos. La primera considera como elemento trascendental la dimensión burocrática del Estado; es decir, mayor coherencia burocrática, así como mayor disposición de recursos e insumos logísticos serían claves para que los Estados puedan adaptarse a la dinámica y funcionamiento de las organizaciones criminales, ergo responder con mayor eficacia a los diversos desafíos de seguridad territorial (Pereira, 2003; Zedner, 2009; Palmer, 1997). De otro lado, la segunda explicación emplea el enfoque State in society (Migdal, 1994) para dar cuenta de cómo muchas intervenciones estatales se tornan efectivas a partir de que las organizaciones sociales controlan parte del proceso de intervención estatal (Romero, 2003). En ese sentido, dicho enfoque teórico considera al territorio como un campo de conflicto donde interactúa una diversidad de actores políticos y sociales, con diversos incentivos y capacidades para ejercer dominación sobre el otro (Migdal, 1994). El caso de la intervención estatal en el valle del Monzón se configura dentro de esta última orientación analítica.

Cabe destacar que en el enfoque de State in society, no se considera a los actores estatales ni los actores sociales como organizaciones cohesionadas y homogéneas en el territorio con capacidad de dominación absoluta. Por el contrario, la asimetría de poder e intereses particulares resultan cotidianos en contextos marcados por la búsqueda de la dominación. En esa línea, las relaciones de poder pueden configurarse en campos de negociación cuando los incentivos y capacidades de los actores estatales y sociales encuentran intereses comunes. Al respecto, Migdal (2011) enfatiza que:

[...] para detectar los patrones de dominación hay que concentrarse en la acumulación de luchas y acuerdos en los múltiples escenarios de la sociedad. Este enfoque solo es posible si se disgregan conceptualmente los Estados y las sociedades, así como los puntos de articulación entre ellos. En algunos casos los resultados de las numerosas luchas pueden impulsar a una sociedad hacia la dominación integrada, en la cual el Estado u otras fuerzas sociales establecen su vasto poder. En otros, los conflictos y complicidades en los múltiples escenarios pueden llevar a la dominación dispersa, donde ni el Estado ni ninguna otra fuerza social logran la dominación a escala nacional, y donde las partes del Estado pueden tirar en direcciones muy diferentes (2011, pp. 127-128).

Más aún, en diversos contextos de inseguridad, los desafíos estatales no pasan únicamente por responder con efectividad frente a actores sociales retadores; es 
decir, frente a aquellos actores que «disputan el derecho del Estado para implementar políticas que han sido adoptadas a través de canales legales» (Eaton, 2012, p. 647) ${ }^{1}$; sino también por articular intereses comunes entre entidades estatales (Richardson, 2000; Sabatier, 1986). No obstante, ya sea por cálculos políticos o por defender la autonomía territorial, en diversos territorios muchas instituciones estatales pueden mostrar una postura crítica frente a las decisiones del Gobierno nacional.

En ese sentido, en diversos contextos de implementación de políticas, la participación de una diversidad de actores no estatales puede resultar clave para los objetivos estatales. Desde organizaciones sociales de base hasta la sociedad civil organizada pueden representar roles importantes en el proceso de ejecución de una decisión estatal (Guibert, Cruz y Figueroa, 2015; García y Valleriestra, 2015). Ahora bien, la participación social en las intervenciones estatales pueden constituirse a través de mecanismos formales de coordinación o simplemente pueden constituirse de manera informal. Ejemplos de esto último se pueden evidenciar con la aparición de comités de autodefensa para combatir a actores ilegales en Perú, Colombia y México (Degregori, Coronel, Del Pino y Starn, 1996; Medina, 1990; Fuentes, 2014).

Por lo tanto, en ciertos contextos, observar la dinámica y el comportamiento de los actores estatales y sociales resulta clave para comprender el proceso de intervención estatal. En la presente investigación se considera que la dinámica de los diversos actores resulta clave para comprender el proceso de la intervención estatal en el valle del Monzón. Dicho proceso está lejos de representar un proceso lineal marcado por la voluntad y capacidad del Estado para dirigir el comportamiento del proceso de la política pública, tal como lo refiere la versión oficial (Devida, 2015). Por el contrario, se sostiene que dicho proceso debe ser comprendido a partir de los diversos contextos donde operaron los actores estatales y no estatales. De esta manera, si bien las acciones de interdicción de la policía antiterrorista, la erradicación de cultivos ilícitos y los programas de desarrollo alternativo constituyen elementos importantes para entender el proceso de control de hoja de coca en el valle del Monzón; también lo fueron las rivalidades internas entre los líderes del gremio cocalero, el enfrentamiento entre bandas criminales de Sendero Luminoso, y la participación de las empresas privadas de la Agencia de los Estados Unidos para el Desarrollo Internacional

Los retadores del Estado pueden ser espaciales o territoriales, y organizacionales o relacionales. Los primeros buscan desplazar a los agentes y/o instituciones de los territorios subnacionales; mientras que los segundos retan al Estado al buscar quebrantar sus intentos de control social (Eaton, 2012, p. 648). 
(USAID) para apoyar el programa de desarrollo alternativo. Todos estos factores, aunque fueron apareciendo uno tras otro por diversos frentes, resultaron ser clave en la explicación del «Modelo Monzón».

\section{Metodología}

El presente artículo constituye un estudio de caso, puesto que se trata de un estudio intensivo de una única unidad (Gerring, 2004). Para ello se realizó trabajo de campo y se aplicaron dos estrategias de recojo de información. Se aplicaron 25 entrevistas semiestructuradas a expertos en materia de drogas, funcionarios públicos — de la Comisión para el Desarrollo y Vida sin Drogas (Devida), la Policía Nacional del Perú (PNP), el Ministerio del Interior (Mininter), el Ministerio de Agricultura (Minagri)—, funcionarios de la cooperación internacional y campesinos cocaleros del Monzón. Complementariamente, se han empleado guías de archivo para la organización de las fuentes periodísticas e informes oficiales.

El proceso de recojo de información se llevó a cabo en tres periodos de tiempo: El primero fue desde abril hasta mayo de 2014, durante el cual se llevó a cabo la revisión documental del caso de estudio. El segundo fue de noviembre a diciembre de 2015, cuando se realizó la primera etapa de entrevistas semiestructuradas en Monzón. El tercero se llevó a cabo en el mes de febrero de 2016, cuando se realizó la segunda etapa de entrevistas.

\section{Hallazgos}

\subsection{Perspectiva oficial de la implementación de la política de drogas en Monzón, 2010-2015}

Antes de la implementación de la política de control de los cultivos ilícitos de coca, eran cuatro los tipos de desafíos que el Estado peruano debía superar en las cuencas cocaleras: i) capturar a los miembros de organizaciones senderistas que operaban en la zona de Monzón, ii) desarticular las organizaciones del tráfico de drogas que financiaban la actividad ilícita, iii) evitar la propagación de protestas campesinas organizadas por el gremio cocalero, y iv) convencer a los campesinos cocaleros para que se adhieran a la política de desarrollo alternativo.

En el valle del Monzón, estos cuatro desafíos se mantuvieron vigentes durante varios años, fundamentalmente porque los diversos intentos de penetración 
territorial del Gobierno nacional se dieron con mucha improvisación y con una limitada capacidad tanto logística como económica para atender los diversos problemas que aparecían en el territorio. Por esta razón, en este valle nunca se había aplicado la erradicación de coca antes de 2013, tampoco existía una constancia en las acciones de captura a organizaciones criminales (véase Tabla 1), y no se implementaron los proyectos de desarrollo alternativo de manera sostenible. Como explica uno de los funcionarios públicos:

Lo de Monzón es reciente, antes nunca se intervino con la misma magnitud de los últimos años. No existía desarrollo alternativo, la policía no entraba, era prácticamente una zona liberada por los cocaleros (Carlos, funcionario de Devida en sede central, 24 de febrero de 2016).

Tabla 1. Operativos policiales de interdicción en Monzón, 2003-2008

\begin{tabular}{|c|l|}
\hline Año & \multicolumn{1}{c|}{ Descripción del operativo } \\
\hline $\begin{array}{c}2003 \\
\text { Operativo } \\
\text { Fierro }\end{array}$ & $\begin{array}{l}\text { Por primera vez, el Estado peruano decide ingresar al valle del Monzón para } \\
\text { realizar acciones de incautación de drogas y erradicación de laboratorios clan- } \\
\text { destinos. Once helicópteros artillados de la Policía Aérea fueron la fuerza de } \\
\text { choque del operativo estatal. }\end{array}$ \\
\hline 2004 & $\begin{array}{l}\text { El operativo duró cinco días y tuvo como objetivo destruir los laboratorios } \\
\text { rústicos para la elaboración de PBC. Se destruyeron más de 125 laboratorios } \\
\text { rústicos para la elaboración de pasta básica de cocaína (PBC) y se neutrali- } \\
\text { zaron 2500 kilogramos de ese estupefaciente en proceso de elaboración. }\end{array}$ \\
\hline $\begin{array}{c}\text { Operativo Monzón } \\
2005\end{array}$ & $\begin{array}{l}\text { El 17 de marzo se realizó un operativo helitransportado de interdicción al } \\
\text { TID. Los sectores intervenidos fueron Maravilla, Consolado, Tazo Pampa, } \\
\text { Puente Unión y Paccha, todos del distrito de Monzón. }\end{array}$ \\
\hline $\begin{array}{c}\text { Operativo Monzón II } \\
\text { Operativo Huracán }\end{array}$ & $\begin{array}{l}\text { La Policía Antidroga de Tingo María y la Dirección de Operaciones Especiales } \\
\text { (DIROES) ejecutaron un operativo en las inmediaciones del caserío Soledad, } \\
\text { en el que destruyeron seis laboratorios para la elaboración de pasta básica de } \\
\text { cocaína. }\end{array}$ \\
\hline Operativo Detector & $\begin{array}{l}\text { El Frente Policial Huallaga realizó incautaciones de estupefacientes en la } \\
\text { carretera que une la ciudad de Huánuco con Áncash. }\end{array}$ \\
\hline
\end{tabular}

Fuente: Elaboración propia a partir de archivos de prensa del diario La República (2004a, 2004b, 2005, 2007), y del diario La Voz (2009).

Sin embargo, a partir del año 2010, esta situación empezó a cambiar. El Gobierno nacional tomó la decisión de intervenir en tres cuencas cocaleras del Alto Huallaga con miras a controlar la producción ilícita de coca y, para ello, incrementó el presupuesto nacional (véanse Gráficos 1, 2 y 3). Con ello, se procedió a financiar la actividad estatal durante el periodo 2010-2015, y, por primera vez en su historia, el Estado promovió la implementación de una política pública con mayor sostenibilidad en el tiempo. 
Gráfico 1. Inversión pública para la erradicación de cultivos ilícitos de coca a nivel nacional, 2013-2015

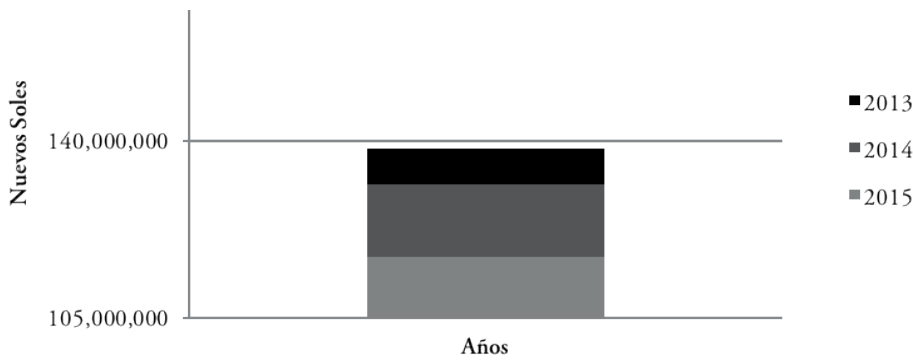

Fuente: Elaboración propia, a partir de Consulta amigable - SIAF del Ministerio de Economía y Finanzas.

Gráfico 2. Inversión pública para el desarrollo alternativo en tres regiones del Alto Huallaga, 2012-2016

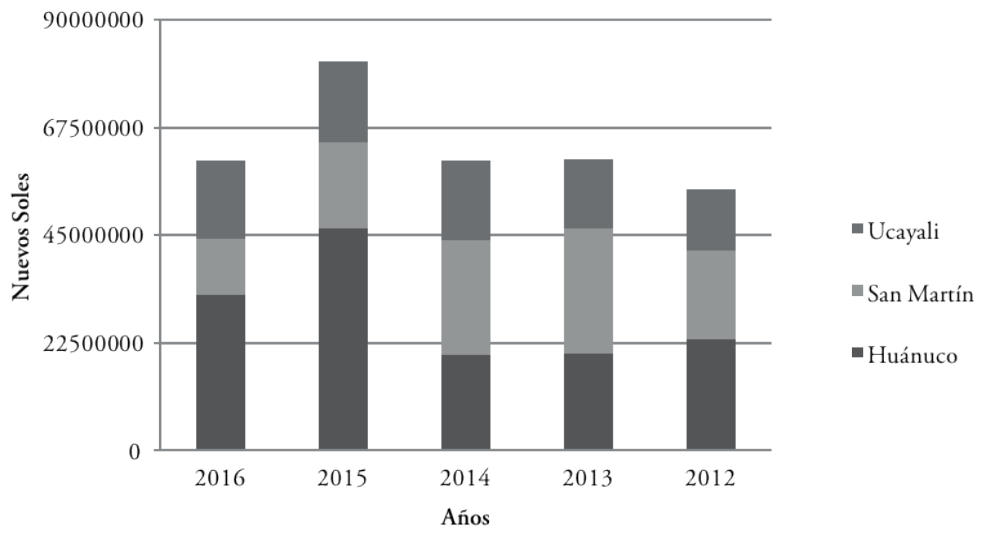

Fuente: Elaboración propia, a partir de Consulta amigable - SIAF del Ministerio de Economía y Finanzas. 


\section{Gráfico 3. Inversión pública de la PNP para acciones de interdicción de drogas en tres regiones del Alto Huallaga, 2012-2016}

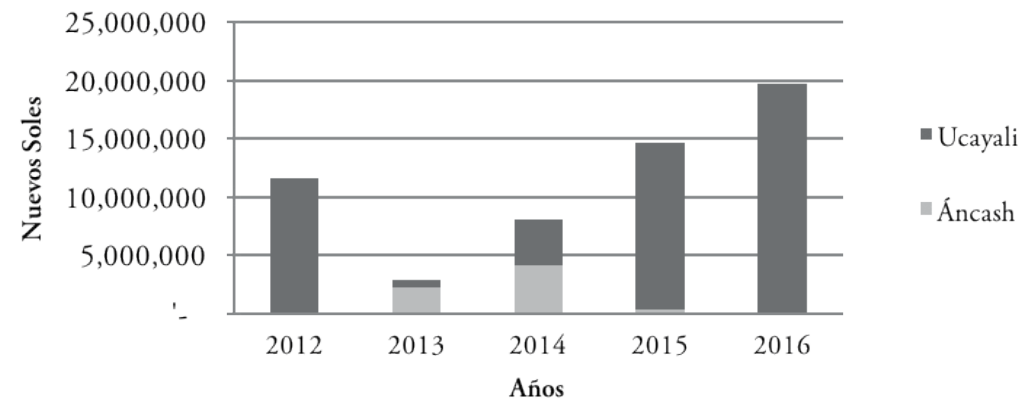

Fuente: Elaboración propia, a partir de Consulta amigable - SIAF del Ministerio de Economía y Finanzas.

Para el Gobierno nacional, son tres las fases que componen el proceso de intervención estatal en Monzón y que determinaría el «Modelo peruano de lucha contra las drogas» (Redacción EC, 2014; Devida, 2015). La primera fase de intervención estuvo centrada en la interdicción de organizaciones criminales vinculadas con el tráfico de drogas y el terrorismo, a cargo de la PNP. La segunda fase estuvo enfocada en la erradicación de las plantaciones de coca, a cargo del Corah ${ }^{2}$. La última fase estuvo centrada en la implementación de proyectos de desarrollo alternativo, intervención que fue liderada por Devida.

La primera fase se realizó entre los años 2008 y 2012, e implicó un trabajo netamente policial. La PNP desarrolló un trabajo de inteligencia durante casi cuatro ańos en Monzón con el objetivo de capturar a diversos sospechosos muchos de ellos dirigentes cocaleros de este valle-, presuntamente vinculados con organizaciones criminales de Sendero Luminoso, e implicados en el tráfico de drogas. Las acciones de inteligencia implicaron desde la interceptación de llamadas telefónicas, la infiltración de agentes policiales en la zona, hasta la captura de organizaciones criminales. En dicho periodo, la PNP capturó a cerca de cincuenta personas vinculadas con los delitos mencionados. Entre dichas personas se encontraba el cabecilla terrorista denominado "Artemio», así como autoridades estatales de la zona.

La segunda fase se llevó a cabo entre los años 2013 y 2016, e implicó el inicio de las acciones de erradicación forzosa de cultivos de coca. El Corah, en coordinación con el Mininter y Devida, ejecutó el Plan Anual de Erradicación

2 Proyecto Especial de Control y Reducción de Cultivos en el Alto Huallaga, agencia estatal dirigida por el Mininter. 
de Coca en Monzón. Las primeras acciones de erradicación se establecieron en caseríos y centros poblados que rodeaban al principal distrito del valle. Según indica un funcionario del Corah, estas actividades se realizaron con miras a demostrar a la autoridad local que el proceso de erradicación no se iba a detener. Durante 2013 se erradicaron alrededor de 4000 ha de cultivos ilegales de coca; en 2014, cerca de 3000 ha y durante 2015 casi 4000 ha (Devida, 2015).

La tercera fase inició a mediados de 2013 y se encuentra en curso hasta la fecha. Esta implicó el comienzo de la implementación de actividades y proyectos de desarrollo alternativo. El Programa de Desarrollo Alternativo consistió en un conjunto de proyectos económicos, sociales y ambientales, cuyo objetivo es generar condiciones territoriales para que los campesinos puedan solventar su economía local alejados de la producción de hoja de coca (Devida, 2015).

En resumen, desde el discurso oficial, la política de drogas implementada en el valle del Monzón adquiere mayor sostenibilidad en el tiempo debido a que el Gobierno nacional comprometió mayores recursos presupuestarios para financiar las actividades de control de las instituciones antidrogas. Con ello, las entidades públicas como la PNP y Devida obtuvieron mayor nivel de eficacia en la gestión de sus intervenciones. Por otro lado, este discurso resalta el papel de las instituciones públicas como agentes principales de la efectividad de la política.

Si bien este recuento de la implementación de la política de drogas en Monzón destaca la importancia de la capacidad burocrática estatal, dicho factor resulta insuficiente para explicar con detalle todos los eventos que ocurrieron durante la intervención estatal. En esa línea, llama la atención que el discurso oficial describa que la intervención estatal en Monzón funcionó fundamentalmente como un proceso coherente de coordinación interna, de principio a fin; sin evidenciar las diversas discrepancias políticas existentes entre las instituciones públicas del Gobierno nacional y subnacional en relación a la política de control de cultivos ilícitos de coca. Cabe cuestionarse, entonces, si a pesar de contar con altos recursos burocráticos, la coherencia interna de las instituciones públicas continuó siendo una limitación para una implementación eficaz de política pública.

\subsection{Debilidades para articular la agenda contra el cultivo de coca al interior del Estado}

De acuerdo al decreto legislativo 824, Devida es la institución rectora de la política de drogas en Perú, adscrita a la Presidencia del Consejo de Ministros; y como tal, tiene la función de coordinar con todas las instituciones del Gobierno nacional y subnacional su diseño e implementación. En términos generales, Devida es la entidad encargada de velar porque todas las instituciones del Estado, 
de acuerdo a sus funciones, comprometan parte de sus recursos económicos en actividades directamente $\mathrm{o}$ indirectamente relacionadas con la lucha antidroga.

Para el caso de Monzón, si bien diversas entidades del Estado han manifestado una actitud favorable a la implementación de la política de control de cultivo de coca, en la práctica, su nivel de involucramiento con la política ha venido variando de acuerdo con la postura que cada una de estas entidades tiene en referencia a la erradicación de hoja de coca y el desarrollo alternativo, generando de esta forma un escenario de participación estatal con cierto nivel de fragmentación (Tabla 2). En este contexto, la política se verá debilitada cuando algunos actores estatales clave, ya sea por su capacidad de recursos económicos o influencia sobre los campesinos cocaleros, no comparten los mismos intereses sobre la política.

Tabla 2. Peso político y postura de los actores estatales y sociales sobre la implementación de la política (2002-2012)

\begin{tabular}{|c|c|c|c|c|c|}
\hline \multirow{2}{*}{$\begin{array}{l}\text { Involucramiento } \\
\text { de los actores con } \\
\text { la implementación } \\
\text { de la política }\end{array}$} & \multicolumn{5}{|c|}{ Postura política de los actores estatales y sociales } \\
\hline & $\begin{array}{l}\text { 1. A favor de } \\
\text { erradicar la } \\
\text { coca }\end{array}$ & $\begin{array}{l}\text { 2. A favor del } \\
\text { desarrollo } \\
\text { alternativo }\end{array}$ & 3. Indiferente & $\begin{array}{l}\text { 4. En contra } \\
\text { de erradicar la } \\
\text { coca }\end{array}$ & $\begin{array}{l}\text { 5. En contra } \\
\text { del desarrollo } \\
\text { alternativo }\end{array}$ \\
\hline ALTA & $\begin{array}{l}\text { Corah } \\
\text { (Mininter) } \\
\text { Devida }\end{array}$ & $\begin{array}{l}\text { Devida } \\
\text { NAV (USAID) }\end{array}$ & $\begin{array}{l}\text { Ministerio de } \\
\text { Transporte } \\
\text { Ministerio } \\
\text { de Comercio } \\
\text { Exterior } \\
\text { Otros } \\
\text { ministerios }\end{array}$ & $\begin{array}{l}\text { Gobierno } \\
\text { local de } \\
\text { Monzón }\end{array}$ & $\begin{array}{l}\text { Gremio } \\
\text { cocalero }\end{array}$ \\
\hline MEDIA & $\begin{array}{l}\text { Policía contra } \\
\text { terrorismo } \\
\text { Policía } \\
\text { antidroga } \\
\text { NAV (USAID) }\end{array}$ & --- & $\begin{array}{l}\text { Comité del } \\
\text { VRAE de } \\
\text { Sendero } \\
\text { Luminoso }\end{array}$ & $\begin{array}{l}\text { Comité del } \\
\text { Huallaga } \\
\text { de Sendero } \\
\text { Luminoso } \\
\text { Campesino } \\
\text { cocalero }\end{array}$ & $\begin{array}{l}\text { Gobierno } \\
\text { local de } \\
\text { Monzón }\end{array}$ \\
\hline BAJA & $\begin{array}{l}\text { Ministerio de } \\
\text { Defensa }\end{array}$ & $\begin{array}{l}\text { Corah } \\
\text { (Mininter) } \\
\text { Minagri }\end{array}$ & $\begin{array}{l}\text { Gobierno } \\
\text { regional de } \\
\text { Huánuco }\end{array}$ & --- & --- \\
\hline
\end{tabular}

Fuente: Elaboración propia a partir de entrevistas en profundidad. 
Si bien Devida cuenta con fondos presupuestales específicos para la agenda antidroga, específicamente para la implementación del desarrollo alternativo, estos fondos no necesariamente cubren todas las necesidades de inversión requerida; en ese sentido, los ministerios cumplen un rol trascendental en la implementación de la política. De acuerdo a lo manifestado por funcionarios de Devida, el papel de los sectores del Gobierno nacional en la política de control de coca en Monzón resulta clave por dos razones. Primero, porque la labor de los ministerios (en específico de los sectores Agricultura, Transporte y Comunicaciones, Saneamiento y Comercio Exterior) es importante para la sostenibilidad de la producción y comercialización de los productos del desarrollo alternativo. En efecto, dichas instituciones son las encargadas de implementar un conjunto de servicios públicos necesarios (como la construcción y mantenimiento de vías, así como de brindar asistencia técnica profesional) que permitan dar soporte a la actividad económica de los productos alternativos; precisamente, muchos campesinos cocaleros han justificado su no adherencia al programa de desarrollo alternativo debido a que no cuentan con las condiciones básicas antes señaladas. En segundo lugar, desde Devida, se consideraba que un alto despliegue de servicios públicos gestionado por las instituciones nacionales en Monzón ayudaría a obtener mayor confianza y legitimidad por parte de los campesinos cocaleros para implementar el control de la hoja de coca; de hecho, se pensaba que con ello se podía atenuar el impacto económico de la erradicación, y en paralelo atenuar posibles rebrotes de resistencia campesina.

Sin embargo, de acuerdo a lo manifestado por funcionarios de Devida, la participación de dichas instituciones no se dio en la magnitud esperada. La mayoría de las instituciones, como el Ministerio de Agricultura, no consideró a la cuenca de Monzón como ámbito prioritario dentro de sus agendas de intervención y por lo tanto, en una primera etapa, Devida iniciaba su intervención con un débil apoyo del Gobierno nacional. Algunos funcionarios de Devida sostienen que este tipo de problemas ocurren debido al débil peso político de su institución para incidir en la agenda institucional de otros ministerios ${ }^{3}$.

Ese ha sido el gran problema del desarrollo alternativo; a los sectores les han interesado muy poco las cuencas cocaleras, no sé si porque tienen otras prioridades o no sé (Carlos, funcionario de Devida en sede central, 18 de septiembre de 2016).

\footnotetext{
3 De acuerdo con Ramírez (2013), si bien existe una postura favorable por parte de las entidades del Gobierno nacional sobre el desarrollo alternativo, en la práctica, salvo Devida y USAID, las instituciones del Estado no suelen tener una participación activa en su implementación.
} 
Yo creo que hoy en día los sectores se están alineando mejor con Devida, ese es el reto y a eso apuntamos (Alberto, funcionario de Devida en sede central, 18 de septiembre de 2016).

Por otro lado, la postura crítica manifestada por diversos alcaldes de Monzón ${ }^{4}$ contra el enfoque de la política de control de coca, también aparecía como una limitación importante para los intereses de Devida. En Monzón, la mayoría de sus gobernantes había formado parte de la agremiación cocalera; y por tanto, cuando alcanzaron la función pública, extendieron su agenda de defensa social contra la política hasta las instancias gubernamentales.

Durante el periodo 2006 hacia adelante, la postura crítica de los gobiernos distritales adquirió mayor resonancia pública, a raíz del liderazgo establecido por los alcaldes Iburcio Morales y Job Chávez. Previo a ejercer dicho cargo, ambos políticos habían ocupado cargos dirigenciales dentro del gremio cocalero de Monzón. En efecto, Morales lideró al movimiento gremial desde 2001 hasta 2005, y fue conocido, entre otros aspectos, por enarbolar el discurso « $i$ Coca o muerte!». Durante su gestión, Morales criticó públicamente al presidente de la República del Perú, en ese entonces Alan García, y a las altas autoridades del Corah, Devida y USAID, por la decisión de continuar implementando acciones de erradicación de hoja de coca. Asimismo, acusó a estas instituciones de desprestigiar la imagen de los ciudadanos de Monzón al calificarlos como «narcotraficantes». Al observar que la erradicación de hoja de coca continuaba y que incluso había llegado hasta la ciudad de Tingo María, Morales decidió intensificar los mecanismos de defensa a través de i) el amedrentamiento a funcionarios de Devida - fundamentalmente a los extensionistas de campo, quienes son profesionales que brindan asistencia técnica a los beneficiarios de los programas implementados por Devida_-, ii) la organización de protestas públicas y movilizaciones contra la erradicación de hoja de coca, y iii) la denuncia a través de medios de comunicación local de presuntos actos de corrupción en los manejos de los fondos provenientes de la cooperación americana. Durante su gestión, Morales estableció fuertes vínculos políticos con altas autoridades del Gobierno provincial de Huamalíes y con el Gobierno regional de Huánuco, quienes públicamente decidieron apoyar la postura asumida por el Gobierno de Monzón.

\footnotetext{
Rosaura Rosales Ramos (1998-2001), Eleodoro Flores Pielago (2002-2005), Iburcio Morales Baltazar (20062011) y Job Chávez Santiago (2012-2014). Una revisión rápida de los planes de gobierno de estos alcaldes permite dar cuenta de su postura favorable hacia la producción de coca. En tanto, Iburcio Morales y Job Chávez enarbolaron la idea de fomentar la industrialización de la coca. Al respecto, véase la web de Infogob dedicada a Monzón (Infogob, s/f).
} 
Por su parte, Job Chávez asumió el mando del gobierno distrital de Monzón luego que Morales fuese encarcelado por la Policía peruana por estar presuntamente vinculado con actividades de terrorismo y narcotráfico. Chávez había ejercido el rol de regidor municipal de Monzón durante la gestión edil de Morales y había participado en todas las actividades de protesta contra la erradicación de coca. Chávez mantuvo dicha postura crítica hasta el final de su mandato. Posteriormente, postuló como candidato municipal para el periodo de gobierno 2015-2018, pero, por asuntos de índole administrativo, fue excluido de dicha contienda electoral. No obstante, según lo manifiestan algunos pobladores, resultaba bastante improbable su reelección toda vez que la población había quedado decepcionada por su débil capacidad para enfrentar la erradicación de hoja de coca que se inició en Monzón en el año 2013.

En 2015, asumió el cargo municipal el ingeniero Víctor Pajuelo, un ciudadano con poca experiencia política y con nulo vínculo con el movimiento gremial cocalero. A diferencia de Morales y Chávez, si bien Pajuelo no manifestó una postura crítica sobre la política de control de coca, es consciente de las limitaciones económicas que presenta el programa de desarrollo alternativo y que, de no fortalecerse, puede conllevar a la reorganización de la protesta cocalera (León, 2016).

En síntesis, la implementación de la política de control de los cultivos de coca se encontraba frente a un escenario donde el Gobierno local estaba controlado por el gremio cocalero, y donde había poco interés por parte de las instituciones nacionales para intervenir con programas sociales y económicos en el territorio. Esta situación reforzaba la postura crítica que tenían los campesinos sobre la política de control de coca, y en paralelo sostenía la desconfianza de los campesinos hacia Devida. Sin embargo, a pesar de todas estas limitaciones, la política se implementó sin los niveles de movilización cocalera esperada 5 .

Como los veremos en la siguiente sección, a pesar de la débil cohesión estatal, la política pudo ser implementada sin enfrentar alta resistencia social, debido al rol que jugaron diversos grupos de actores no estatales. Dichos grupos contribuyeron en debilitar la capacidad de movilización campesina cocalera debilitando el vínculo entre Sendero Luminoso con el gremio cocalero, y agudizando la desconfianza entre campesinos con el Gobierno local—, así como

\footnotetext{
5 Situación similar ocurrió durante el proceso de implementación de la política de control de coca en la zona denominada como Boquerón de Padre Abad (Ucayali). Entre los años 2001 a 2008, el Estado intentó controlar la producción de hoja de coca con erradicación y desarrollo alternativo, pero la desarticulación de intereses estatales en la agenda anticoca y la fuerte cohesión local de campesinos cocaleros en contra de la política, originó que la política sea resistida mediante una serie de protestas sociales, con altos niveles de violencia física contra funcionarios públicos. Para mayor información revisar el texto de Laurente (2010).
} 
también en apoyar a Devida en la implementación del desarrollo alternativo (principalmente fortaleciendo el vínculo entre campesinos cocaleros y Devida).

\subsection{Tres escenarios de acción social y su impacto en la cohesión cocalera}

\section{Disputas entre las facciones de Sendero Luminoso}

La captura de Artemio y la de otros miembros senderistas en el Huallaga representó un fuerte impacto para los intereses del gremio cocalero de Monzón. Tal como lo señalan diversos funcionarios de la PNP, el vínculo establecido entre ambas organizaciones se había centrado fundamentalmente en la defensa armada de la producción ilícita de coca y de los derivados cocaínicos.

Con la captura del camarada Feliciano, existe un giro estratégico del plan de continuidad de la lucha armada. Esta vez, empleando los recursos del narcotráfico para financiar la organización del partido hasta que se tenga la certeza de retomar la guerra de guerrillas (Ginés, funcionario de la PNP, 17 de junio de 2015).

Si había una relación, pero era más de índole personal. Mis informantes le habían hecho seguimiento a Clay y en ese seguimiento se identificó que guardaba mucha comunicación con el señor Iburcio Morales. Entonces, si había, y eso es una de las cosas que no solo lo decimos nosotros porque también la fiscalía lo dice y por eso va preso (Luis, funcionario de la Policía contra el terrorismo, 09 de septiembre de 2016).

Si bien la labor de la PNP resultó central para la desarticulación y captura de los remanentes terroristas, es importante destacar que durante el periodo de 2010 a 2012 existió una disputa armada entre los grupos terroristas de Sendero Luminoso del Huallaga y del VRAE. Dicha disputa favoreció al debilitamiento del grupo senderista del Huallaga; lo cual, posteriormente, fue aprovechado por las fuerzas del orden.

Luego de la captura de Abimael Guzmán, principal líder de la agrupación terrorista de Sendero Luminoso, dicha organización criminal quedó dividida en dos frentes de repliegue: el primer frente estaba dirigido por el Comité Regional del Huallaga, el cual estaba liderado por el terrorista Artemio desde mediados de la década de 1990. El segundo frente estaba dirigido por el Comité Regional Principal del Centro (VRAE), a cargo del terrorista José Quispe Palomino. A pesar de que ambos grupos han confirmado su adherencia a Sendero Luminoso, diversos elementos del contexto permiten evidenciar algunos contrastes ideológicos tales como su posición respecto a la continuidad de la lucha armada, su vínculo con líderes históricos de la organización y su discurso respecto al tráfico de drogas (véase Tabla 3). 
Tabla 3. Contrastes ideológicos entre Sendero Luminoso del Huallaga y del VRAE

\begin{tabular}{|l|l|}
\hline \multicolumn{1}{|c|}{ Comité Regional del Huallaga } & \multicolumn{1}{c|}{ Comité Regional del Centro } \\
\hline Continuidad de la lucha armada & Se descarta la continuidad de la lucha armada \\
\hline $\begin{array}{l}\text { Vinculación manifiesta con líderes históricos de } \\
\text { Sendero condenados }\end{array}$ & $\begin{array}{l}\text { Ninguna vinculación con líderes históricos de } \\
\text { Sendero }\end{array}$ \\
\hline Discurso crítico sobre el narcotráfico & $\begin{array}{l}\text { Ninguna manifestación crítica sobre el } \\
\text { narcotráfico }\end{array}$ \\
\hline
\end{tabular}

Fuente: Elaboración propia a partir de entrevistas en profundidad a funcionarios de la Policía contra el terrorismo.

Las diferencias entre las facciones de Sendero Luminoso del Alto Huallaga y del VRAE se hicieron evidentes por medio de las declaraciones que emitieron los líderes terroristas a los medios de comunicación (IDL, 2010). Artemio no consideraba al grupo terrorista del VRAE como una fuerza aliada, sino como una agrupación de «mercenarios» que se habían alejado de la ideología del partido comunista. En específico, el líder del Alto Huallaga señaló lo siguiente: «Mi posición es de deslinde, de repudio, de rechazo y condena a este grupo mercenario del VRAE, liderado por estos dos mercenarios (los hermanos Quispe Palomino)»(IDL, 2010).

El distanciamiento entre ambos bandos terroristas se agudizó entre los años 2010 y 2012, cuando los hermanos Quispe Palomino decidieron llevar a cabo un plan para asesinar a Artemio (Aguirre, 2013a, 2013b; RPP, 2010). Durante ese periodo, el poder armado del Comité Regional del Huallaga se encontraba debilitado debido al control establecido por las fuerzas del orden. Según los funcionarios de la PNP, es posible establecer al menos dos intentos de asesinato.

El primer intento se llevó a cabo en el año 2011, cuando el camarada «Manuel» movilizó alrededor de 145 senderistas desde el Vizcatán hacia Monzón y Aucayacu. Además del asesinato de Artemio, se pretendía instaurar un nuevo liderazgo en Huallaga, con miras a contar con una persona de confianza. Sin embargo, este primer intento de control del Monzón se vio frustrado debido a que Artemio tomó conocimiento de dicha movilización y procedieron rápidamente a ocultarse en la comunidad de Shambillo. La movilización de una importante cantidad de miembros de la agrupación subversiva del VRAE produjo que las unidades de inteligencia de las fuerzas del orden tomaran conocimiento del plan de asesinato. Ante ello, dicho grupo terrorista procedió a replegarse a fin de no desatar un enfrentamiento con la Policía. 
El segundo intento de asesinato se llevó a cabo a fines de 2011, cuando un grupo armado de aproximadamente 25 terroristas liderado por el camarada "Alipio» se movilizó hacia el caserío de Bolsón Cuchara en búsqueda de Artemio. Según lo manifiestan diversos funcionarios de inteligencia de la Dirección Contra el Terrorismo de la PNP, un grupo de senderistas del Huallaga había traicionado a Artemio ofreciendo información sobre su paradero a los hermanos Quispe Palomino. En esta segunda oportunidad, sí ocurrió un enfrentamiento armado entre ambos bandos senderistas, lo cual originó que Artemio perdiera una mayor cantidad de hombres armados. Al verse acorralado tanto por la Policía como por la facción senderista del VRAE, Artemio se vio obligado a ocultarse en la localidad de Santa Rosa de Mishollo, ubicada en la ciudad de Tocache (San Martín).

Si bien los intentos de asesinato a Artemio no se concretaron, el impacto de ambas movilizaciones debilitó ampliamente al brazo armado del grupo senderista del Huallaga. Muchos terroristas abandonaron el territorio con rumbo desconocido, en tanto Artemio decidió ocultarse hasta su posterior captura (en febrero de 2012). Con un brazo armado debilitado, y perseguido por las fuerzas del orden y el grupo terrorista del VRAE, los espacios de movilización de Artemio empezaron a extinguirse.

\section{Desconfianza hacia el gremio cocalero}

Desde 2003, el gremio cocalero de Monzón se había ganado el reconocimiento de constituirse como la organización más poderosa y estructurada del movimiento cocalero del Perú. Para ello, había resultado clave la fuerte confianza entre el gremio cocalero y los campesinos, con miras a establecer diversos mecanismos de movilización social frente a las acciones de control de coca ilícita. Dicha relación se mantuvo estable hasta el año 2013, cuando los campesinos cocaleros empezaron a desvincularse del liderazgo del gremio cocalero. Con el movimiento cocalero sin capacidad de liderazgo y movilización social, el Estado pudo tener mayor espacio para implementar los proyectos de desarrollo alternativo.

Previo a las actividades de erradicación de hoja de coca, el gremio cocalero de Monzón era reconocido como una de las organizaciones de defensa de la coca más importantes del Huallaga. Dicho reconocimiento se le entregaba por demostrar alta capacidad para organizar movilizaciones locales contra la erradicación de la coca, donde también se comprometía a casi el total de la población de la zona; así como por su capacidad para proveer resguardo territorial contra el ingreso de policías y otros funcionarios estatales. 
Me acuerdo que se hacían llamar "La Poderosa», ellos así se decían; prácticamente, como quien dice, ellos marcaban la pauta de qué se hacía, qué no se hacía, quién entraba. Nadie podía hacer nada sin su permiso (Julio, funcionario de Devida en Tingo María, 06 de agosto de 2014).

Progresivamente, el gremio cocalero de Monzón fue adquiriendo autonomía frente a las demás organizaciones de defensa de la coca. Inicialmente, existía una sola organización gremial que incluía tanto a los valles del Alto Huallaga y de Padre Abad, denominada «Asociación de Agricultores y Productores de Hoja de Coca del Alto Huallaga, Monzón y Padre Abad» (AAPHC-AHMPA). No obstante, posteriormente, el gremio cocalero de Monzón decidió conformar una organización individual, denominada Comité de Productores Agropecuarios del Valle del Monzón; aunque finalmente procedió a modificar su nombre para convertirse en la Poderosa Federación de Cocaleros del valle del Monzón (van Dun, 2009).

La fuente de financiamiento del gremio provenía fundamentalmente del aporte que cada campesino otorgaba periódicamente. Si bien no fue posible constatar la existencia de una tasa fija de recaudación, diversos campesinos manifiestan que la periodicidad del pago podía variar de acuerdo a la magnitud de las ganancias obtenidas por las cosechas que reportaba cada campesino, así como por otras tasas que de manera coyuntural imponía el gremio cocalero.

$\mathrm{Si}$, te pedían y uno les daba porque ellos decían que aquí no iba a venir la Corah porque ellos estaban preparados (Vera, campesina cocalera de Cachicoto, Monzón, 09 de mayo de 2015).

Te sacaban plata, te pedían y si no les dabas se molestaban. Varias veces me decían que si no pagaba me tenía que largar, uno tenía que al final darle no más (José, campesino cocalero cochero de Palo Wimba, Monzón, 09 de mayo de 2015).

A partir del debilitamiento del Comité Regional del Huallaga de Sendero Luminoso y la captura de varios miembros del gremio cocalero, la organización cocalera de Monzón empezó a perder autoridad frente a los campesinos. En adelante, muchos productores cocaleros dejaron de aportar al gremio, y tampoco atendieron los diversos llamados a una movilización local con miras a detener las acciones de erradicación. Mientras un grupo de campesinos cocaleros acusaba al gremio de no haber hecho lo necesario para evitar la erradicación forzosa, otro grupo más bien resaltaba los diversos abusos de poder a los que se sometían mientras el gremio cocalero lideraba en Monzón.

El abuso yo diría venía más porque ellos te decían que te iban a defender de la erradicación, pero luego ellos mismos te amenazaban, te pedían plata a cada rato (Apac, campesina cocalera cochero de Cachicoto, Monzón, 10 de mayo de 2015). 
Yo varias veces le pregunté a la gente y me decían no, ingeniero la verdad que nos sentimos amordazados, esto es un caos. Yo sí creo que ellos no estaban felices con el gremio cocalero, pero, claro, solo ellos ofrecían defenderlo de la coca, así que a nada lo aceptaban (Jesús, funcionario de Devida en Tingo María, 11 de mayo de 2015).

Hoy en día el gremio de cocaleros de Monzón permanece débil y sin liderazgo político. En 2014, después de varios años de hegemonía cocalera, un ciudadano no cocalero es elegido como alcalde del distrito de Monzón (León, 2016). Asimismo, conforme avanza el tiempo, diversas familias campesinas han empezado a desvincularse del cultivo de coca y empiezan a desarrollar los proyectos generados por el programa de desarrollo alternativo.

\section{Empresas privadas y desarrollo alternativo}

En términos generales, el programa de desarrollo alternativo es un paquete de medidas económicas, sociales, ambientales y políticas, impulsadas para hacer sostenible el proceso de sustitución de cultivos en las cuencas cocaleras (Devida, 2015). Formalmente, el Estado peruano introdujo el programa de desarrollo alternativo a mediados de la década de 1990; sin embargo, fue a partir de principios del siglo XXI que se insertó como una estrategia de control de drogas (Maldonado, 2009).

Actualmente, el programa de desarrollo alternativo es liderado por Devida. No obstante, desde 2001 dicho programa ha venido siendo financiado por las instituciones de cooperación internacional, principalmente por la cooperación estadounidense USAID (Maldonado, 2009). Históricamente, USAID ha jugado un papel central en la implementación del desarrollo alternativo; muchos especialistas en la materia sostienen, por ejemplo, que el éxito del programa de desarrollo alternativo en la región San Martín se debe al trabajo organizado de USAID. Por el contrario, históricamente, el papel de Devida ha sido débil, centrándose netamente en la coordinación financiera del programa (Maldonado, 2009; Cabieses, 2008).

Si bien en los últimos cinco años el Estado peruano incrementó sustancialmente sus recursos económicos para la implementación del programa de desarrollo alternativo, la participación de USAID continuó siendo fundamental. Ello en tanto, por un lado, esta agencia disponía de personal experimentado para intervenir en territorios cocaleros, $y$, en segundo lugar, porque ayudaba a cubrir la débil participación de las diversas instituciones que componen los sectores del Gobierno nacional.

Para intervenir en el territorio, USAID contrató a un conjunto de empresas privadas y organizaciones sin fines de lucro. Diversas empresas tuvieron un 
papel importante dentro del desarrollo alternativo; empero, el Programa de Nuevas Alternativas (NAV) jugó un papel clave en el Monzón. En efecto, NAV y Devida desarrollaron un trabajo conjunto altamente coordinado. Si bien el papel de NAV estaba centrado en el componente social y comunitario, por ejemplo generando reuniones de coordinación con los campesinos cocaleros para incentivarlos a que se vinculen con el desarrollo alternativo, así como organizando la conformación de juntas vecinales con los líderes locales, también se involucró en el desarrollo de actividades agrícolas.

El recurso humano de NAV estaba compuesto por un conjunto de profesionales con amplia experiencia en la implementación del desarrollo alternativo. Muchos de ellos, por ejemplo, habían formado parte de la empresa Chemonics, que entre los años 2003 a 2007 fue contratada por USAID para desarrollar actividades en las cuencas cocaleras de Tocache y Padre Abad.

Eso siempre ha sido así y además, aunque hay críticos, históricamente USAID es el socio que mayores aportes le ha dado al desarrollo alternativo, es innegable (Carlos, funcionario de Devida en sede central, 07 de septiembre de 2016).

Tú has visto que todo se hace en coordinación con Devida, y siempre vamos a decir que todos somos Devida (Jesús, funcionario de Devida en Tingo María, 11 de mayo de 2015).

Si bien Devida lideró la ejecución del desarrollo alternativo, las empresas de USAID, como NAV, resultaron claves para alcanzar las metas y objetivos programados.

\section{CONCLuSiones}

Si bien la producción académica sobre las diversas experiencias de intervención estatal en cuencas cocaleras ha sido extensa (Villarán, 2012; Macroconsult, 2008; Cabieses, 2010; Maldonado, 2009; García, 2013; entre otros), por lo general el análisis desarrollado se ha centrado fundamentalmente en dos perspectivas: por un lado, en una lectura histórica del proceso de intervención, y de otro lado, una perspectiva crítica al enfoque de la estrategia de intervención estatal. Más allá de las particularidades de cada investigación, en términos generales, lo estudios han abordado el fenómeno desde una perspectiva Estadocéntrica, donde pocas veces se ha tomado en consideración los roles que han cumplido los actores sociales dentro del contexto de intervención pública. De igual forma, salvo algunas excepciones (Zevallos, 2016), las investigaciones pocas veces han evidenciado las diversas disputas internas que existen entre las instituciones públicas respecto al objetivo del control de la hoja de coca. 
La presente investigación propone cubrir ambos vacíos a partir de una lectura crítica del proceso de intervención de la política de control de cultivo de coca aplicada en el valle del Monzón durante el periodo 2010-2015. Para ello nos hemos centrado en el análisis de los roles que cumplen los diversos actores estatales y sociales durante el contexto de intervención. El caso de estudio demuestra que la efectividad en la implementación de dicha política no necesariamente se debe a la mejora en la capacidad de recursos burocráticos del Estado, sino por el rol que jugaron diversos actores sociales para fortalecer la gestión operativa de la política del desarrollo alternativo y evitar la movilización del movimiento cocalero frente a las acciones de erradicación.

La débil articulación entre el ente rector antidrogas de Perú con otras entidades del Gobierno nacional para la implementación del desarrollo alternativo, así como la posición crítica asumida por el Gobierno local de Monzón contra la política de erradicación, ponía en riesgo la sostenibilidad de la política de control de cultivo de coca, frente a una posible movilización cocalera con capacidad para paralizar las actividades de control. Sin embargo, esto no ocurrió así, debido a que la capacidad de movilización cocalera se vio debilitada por diversas confrontaciones que afectaron directamente e indirectamente en su estructura.

En ese sentido, son tres los eventos clave que ayudaron a definir el resultado de la política: En primer lugar, el enfrentamiento interno entre dos organizaciones terroristas que brindaban protección armada para la defensa de los cultivos de coca. En segundo lugar, el resquebrajamiento interno de las relaciones de confianza entre el gremio cocalero y los campesinos de Monzón. Por último, la participación activa de una empresa privada en la implementación del programa de desarrollo alternativo.

De esta manera, pese a las limitaciones burocráticas y de articulación gubernamental que mantiene Devida para implementar las acciones de control del cultivo de coca, dicho proceso se mantiene estable en el territorio y ha logrado disminuir la intensidad de producción de hoja de coca ilícita.

\section{REFERENCIAS}

Cabieses, Hugo (2008). Política de drogas: cuatro aciertos, cinco continuidades y ninguna propuesta seria. En E. Toche (comp.), Perú Hoy. Por aqui compañeros. Aprismo y neoliberalismo (pp. 359-383). Lima: Desco.

Cabieses, Hugo (2010). El 'Milagro de San Martín' y los síndromes del 'desarrollo alternativo' en el Perú. Informe sobre política de drogas 34. Transnational Institute. https://www.tni.org/files/ download/brief34s.pdf 
Cabieses, Hugo (2000). Ruralización del 'desarrollo alternativo' en el Perú: debates, tipologías y reconsideraciones. En Memorias del seminario internacional "La Nueva Ruralidad en América Latina”. Bogotá: Pontificia Universidad Javeriana-Facultad de Estudios Ambientales y RuralesMaestría en Desarrollo Rural-Departamento de Desarrollo Rural y Regional. http://www.cepes. org.pe/cendoc/eventos/Libro-Foro-Reforma-Agraria-2007/11-\%20cabieses-peru.pdf

CVR-Comisión de la Verdad y la Reconciliación (2003). El PCP-SL durante el auge de la droga en el Alto Huallaga. Informe Final, Tomo V (pp. 186-208). Lima: Comisión de la Verdad y Reconciliación.

Davis, D. E. (2003). Contemporary Challenges and Historical Reflections on the Study of Militaries, States and Politics. En E. Davis y A. W. Pereira, Irregular Armed Forces and Their Role in Politics and State Formation (pp. 3-35.). Cambridge: Cambridge University Press. https://doi. org/10.1017/CBO9780511510038.002

Degregori, C.I., Coronel, J., Del Pino, P. y Starn, O. (1996). Las rondas campesinas y la derrota de Sendero Luminoso. Lima: Instituto de Estudios Peruanos.

Dell, M. (2015). Trafficking Networks and the Mexican Drug War. American Economic Review, 105(6), 1738-1779. https://doi.org/10.1257/aer.20121637

Eaton, K. (2012). The State of the State in Latin America: Challenges, Challengers, Responses and Deficits. Revista de Ciencia Politica, 32(3), 643-657. https://doi.org/10.4067/ S0718-090X2012000300008

Felbab-Brown, V. (2009). Shooting Up. Counterinsurgency and the War on Drugs. Washington: Brookings Institution Press.

Fuentes, A. (2014). Autodefensa y justicia en los márgenes del Estado. Revista Clivajes, (2). Instituto de Ciencias Sociales y Humanidades de la Benemérita Universidad Autónoma de Puebla.

García, J. (2013). La situación del narcotráfico en la región Huánuco. Serie Amenazas a la Seguridad: El Narcotráfico. Documento 16. Lima: IDEI PUCP.

García, L. y Valle Riestra, E. (2015). Entre balas y ladrillos: reacciones del Estado ante la violencia en el sector de construcción civil. Paper presentado en VIII Congreso Latinoamericano de Ciencia Politica ALACIP. Lima: PUCP.

Gerring, John (2004). What is a case study and what is it good for? American Political Science Review, 98(2), 341-354. https://doi.org/10.1017/S0003055404001182

Giraudy, A. y Luna, J. P. (2012). An Explanatory Typology of State's Territorial Reach: State actors and territorial challengers in Latin America. New Orleans: APSA-Meeting.

Guibert, Y., Cruz, M. y Figueroa, M. (2015). La modernización del puerto del Callao: La respuesta del Estado a la ola exportadora 2004-2011. Revista de Ciencia Politica y Gobierno, 2(4), 101-127.

Kernaghan, R. (2009). Coca's Gone. Of Might and Right in the Huallaga Post-Boom. Stanford: Stanford University Press.

Laurente, D. (2010). Los movimientos cocaleros y las políticas públicas en la lucha antidrogas del Perú, el caso del valle del Río Aguaytía: 2001-2004. Tesis de grado. Documento inédito. Lima: Universidad Nacional Mayor de San Marcos

León, R. (2016). Coca o muerte, postularemos. El ritmo electoral en el VRAE y el Alto Huallaga. En C. Meléndez (ed.), Anti-candidatos. El thriller político de las elecciones 2016. Lima: Planeta.

Lombard, L. (2015). State of Rebellion: Violence and Intervention in the Central African Republic. Londres: Zed Books.

Macroconsult (2008). Narcotráfico: amenaza al crecimiento sostenible del Perú. Lima: Forma e Imagen.

Maldonado, L. (2009). El desarrollo alternativo dentro de la estrategia antidrogas modelos de intervención del PDA. Documento inédito. Lima: Devida. 
Medina, C. (1990). Autodefensas, paramilitares y narcotráfico en Colombia. Origen, desarrollo y consolidación. El caso "Puerto Boyacá". Bogotá: Editorial Documentos Periodísticos.

Migdal, J. (1994). State Power and Social Forces: Domination and Transformation in the Third World. Cambridge: Cambridge University Press. https://doi.org/10.1017/CBO9781139174268

Migdal, J. (2011). Estados débiles, Estados Fuertes. México DF: Fondo de Cultura Económica.

Palmer, D. (1997). When tolerance is zero. Alternative Law Journal, 22(5), 232-236.

Pereira, A. W. (2003). Armed Forces, Coercive Monopolies, and Changing Patterns of State Formations and Violence. En D. E. Davis y A. W. Pereira, Irregular Armed Forces and Their Role in Politics and State Formation (pp. 387-408). Cambridge: Cambridge University Press. https:// doi.org/10.1017/CBO9780511510038.016

Ramírez, M. (2013). La alineación a la política de "coca cero" durante el gobierno de Alejandro Toledo (2001-2003): La priorización del programa de erradicación de cultivos ilicitos de hoja de coca, en el marco de la Estrategia Nacional de Lucha contra las Drogas en Perú. Tesis de grado en Ciencia Política. Pontificia Universidad Católica del Perú. Documento inédito.

Ribando, C. (2014). Gangs in Central America. Washington: Congressional Research Service.

Richardson, J. (2000). Government, interest groups and policy change. Political Studies, 48(5), 1006-1025. https://doi.org/10.1111/1467-9248.00292

Romero, M. (2003). Reform and reaction: Paramilitary groups in contemporary Colombia. En D. E. Davis y A. W. Pereira, Irregular Armed Forces and Their Role in Politics and State Formation (pp. 178-208). Cambridge: Cambridge University Press. https://doi.org/10.1017/ CBO9780511510038.008

Sabatier, P. (1986). Top down and bottom-up approaches to implementations research: A critical analysis and suggested synthesis. Journal of Public Policy, 6(1), 21-48. https://doi.org/10.1017/ S0143814X00003846

Scott, J. (1985). Weapons of the Weak: Everyday Forms of Peasant Resistance. Connecticut: Yale University Press.

Van Dun, M. (2009). Cocaleros. Violence, Drugs and Social Mobilization in the Post-Conflict Upper Huallaga Valley, Peru. Tesis de Doctorado. Utrecht University Repository. https://dspace.library. uu.nl/handle/1874/33733

Villarán, F. (2012). El Modelo de Desarrollo Alternativo de la Región San Martín. Un caso de Desarrollo Económico Local. Lima: UNODC.

Zedner, L (2009). Security. Nueva York: Routdledge.

Zevallos, N. (2016). Capacidades estatales y resistencias a la erradicación de cultivos: una mirada al Monzón. RITA-Revue Interdisciplinaire de Travaux Sur les Amériques, (9). Recuperado de: http:// www.revue-rita.com/notesderecherche $9 /$ capacidades-estatales-y-resistencias-a-la-erradicacionde-cultivos-una-mirada-al-monzon.html

Zevallos, N. (2014). Hoja de coca y la Estrategia Nacional de Lucha contra las Drogas 20072011: el problema público en el control de cultivos. Revista de Ciencia Politica y Gobierno, 1(1), 97-113.

\section{Informes}

Devida-Comisión Nacional para el Desarrollo y Vida sin Drogas (2015). Recuperando el Monzón. Lima: Observatorio Peruano de Drogas (OPD).

Devida-Comisión Nacional para el Desarrollo y Vida sin Drogas (2013). Diagnóstico socio económico y ambiental de la cuenca baja del valle del rio Monzón. Lima: Dirección de Promoción y Monitoreo (DPM).

Infogob (s/f). Monzón. Web Observatorio para la gobernabilidad. http://www.infogob.com.pe/ Localidad/ubigeo.aspx?IdUbigeo=090407\&IdLocalidad=464\&IdTab=1 


\section{Fuentes periodísticas}

Aguirre, Doris (9 de abril de 2013a). "Camarada Leo”, el terrorista que delató y entregó al número 4 de SL en el Vraem. Diario La República. http://larepublica.pe/09-04-2013/camarada-leo-elterrorista-que-delato-y-entrego-al-numero-4-de-sl-en-el-vraem. Última fecha de consulta: 21 de julio de 2017.

Aguirre, Doris (18 de julio de 2013b). Nancy Obregón alistaba reemplazo de "Artemio" por terrorista del Vraem. Diario La República. http://larepublica.pe/18-07-2013/obregon-alistabareemplazo-de-artemio-por-terrorista-del-vraem. Última fecha de consulta: 21 de julio de 2017.

Diario La República (2004a). Nadie puede erradicar sembríos de hoja de coca en el valle del Monzón. Diario La República. Edición impresa del 18 de febrero de 2004.

Diario La República (2004b). Destruyen sesenta laboratorios de narcoterroristas en Tingo María. Diario La República. Edición impresa del 09 de octubre de 2004.

Diario La República (2005). APRA sí apoya erradicación de cultivos ilegales de coca. Diario La República. Edición impresa del 10 de setiembre de 2005.

Diario La República (2007). Narcoterroristas cobraban cupos en zona de Huallaga. Diario La República. Edición impresa del 15 de agosto de 2007.

Diario La Voz (2009). Narcos fugan abandonando kerosene. Diario La voz. Edición impresa del 23 de diciembre de 2009.

IDL-Reporteros. (18 de diciembre de 2010). "Artemio": Lo que revela el vídeo. IDL-Reporteros. Recuperado de https://idl-reporteros.pe/artemio-lo-que-revela-el-video/. Última fecha de consulta: 21 de julio de 2017.

Redacción EC (23 de octubre de 2014). La valla alta del Monzón, por Alberto Otárola Peñaranda. Diario El Comercio. http://elcomercio.pe/opinion/colaboradores/valla-altamonzon-alberto-otarola-penaranda-noticia-1765694. Última fecha de consulta: 21 de julio de 2017.

RPP-Radio Programas del Perú (27 de enero de 2010). Revelan pugnas entre Artemio y camarada "José" por liderazgo de Sendero. RPP Noticias. http://rpp.pe/peru/actualidad/revelanpugnas-entre-artemio-y-camarada-jose-por-liderazgo-de-sendero-noticia-238288. Última fecha de consulta: 21 de julio de 2017. 